\title{
METHODOLOGY OF NON-LINEAR ROBUST ESTIMATION FOR THE SOLUTIONS SYNTHESIS OF INVERSE AND DIRECT MULTIDISCIPLINARY PROBLEMS IN ENGINEERING DIMENSIONAL CHAINS CALCULATION BASED ON DISCRETE ANALOG DATA
}

\author{
I. TROFYMOVA, I. MENIAILOV, S. CHERNYSH, S. YEPIFANOV, \\ O. KHUSTOCHKA, M. UGRYUMOV, A. MYENYAYLOV, D. CHUMACHENKO
}

\begin{abstract}
This paper analyses the definition of inverse and direct problems in engineering dimensional chains calculation based on discrete analogue data and the methodologies for solving these problems. It is shown that the direct dimensional chains calculation, which belongs to the class of inverse boundary value problems in a stochastic formulation, can be transformed into multi-criteria problems of stochastic optimization with mixed conditions. The new multi-step solutions search methodology for these problems is based on non-linear robust estimation methods. It can be achieved through hierarchical two-level decisions synthesis scheme development. At the first step, this scheme includes identification of surrogate models (in the form of regression equations). At the second step, the effective robust estimates are computed to determine unknown values; estimations of unknown quantities are carried out under a priori and parametric data uncertainties. Results of calculations of inverse and direct problems in engineering dimensional chains for two-stage axial compressors are presented. They were obtained using interactive computer systems for decision-making support "ROD\&IDS".
\end{abstract}

Keywords: inverse boundary value problems in a stochastic formulation, a priori and parametric uncertainties, methods and systems for estimating quantities and processes, decision-making theory.

\section{INTRODUCTION}

Cost-cutting of the systems refinement is one of the most relevant issues in the processes of project development and operation in state-of-the-art technology. It should be noted that a good exact solution of the inverse problem in a deterministic formulation (optimization problem) in practice during mass production, as a rule, leads to a large scatter of the values of the integral characteristics of products. Then there is selective assembly or rejection of products for quality. It is possible to resolve this general technical problem by putting the Robust Estimation methods into practice.

The examples of partial problems that form this general problem are:

- choice of equipment with a certain degree of accuracy for manufacturing products (this will reduce the percentage of failures in serial production and avoid selective assembly of products);

(c) I. Trofymova, I. Meniailov, S. Chernysh, S. Yepifanov, O. Khustochka, M. Ugryumov, A. Myenyaylov, D. Chumachenko, 2020 
- choice of measuring systems components with a certain degree of accuracy, which will ensure the specified measurement accuracy of controlled variables of systems and processes;

- intelligent diagnostics of systems and processes based on monitoring of controlled state variables;

- prediction of the condition of patients in medical monitoring systems, choice of an individual treatment program for each of them;

- development of new drugs in the pharmaceutical industry;

- robust optimal control of systems and processes;

- machine-building including the product quality control (Design for Six Sigma), and also the areas of industrial safety, ecology, the activities of banks, insurance, audit, etc.

The following mathematical issues arise in the process of the abovementioned systems development: uncertainties evaluation, structuring of the regularizing algorithms, and high computational complexity of methods for quasisolutions synthesis under uncertainties.

Such inverse problems are essentially ill-posed since it is not known in which class of functions to search for the solutions and there are uncertainty deals with the choice of the exact solution. However, these problems can be reduced to conditionally well-posed.

Such an approach of reducing inverse problems to structural-parametric optimization problems at stochastics formulation, and for a given structure - to multi-parameter optimization problems in a stochastics formulation is widely used in practice. The synthesis of solutions to such problems is performed using regularization methods based on machine learning algorithms.

The outcomes of this research are the development of new solutions synthesis methods for the stochastic optimization problems with mixed conditions and development of the software which implements them and can be used for practical problem-solving.

One problem is that during the development of state-of-the-art technic objects, it is necessary to take into account a optimal set of design parameters of system elements as well as their resource issues. All these factors form the basis for technological processes formation in manufacturing. For example, nowadays the ratio of the technical defect in gas turbine engine blades manufacturing is around $5 \%$, but it can reach $20 \%$ when the blades are checked under their workload frequency. The quality of computation has a direct effect on the manufacturing and operation quality of elements and whole systems.

Another problem is related to manufacturing tolerances that are a part of the design technology. Initially, the tolerances are defined, and then the manufacturing technology is designed to meet them. The technological manufacturing tolerances selection scheme is presented in Fig. 1. The technological tolerances of system elements manufacturing are defined by the given values of confidence intervals of design parameters, the junction type, the seating fit, the processing equipment accuracy rating, and the assembly type. The confidence intervals of design parameters are formed as the result of engineering dimension chains calculation. 


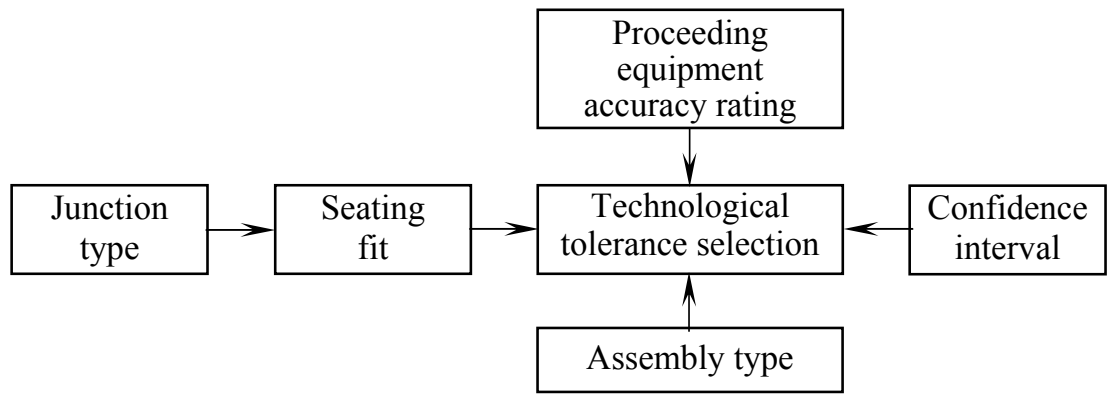

Fig. 1. Scheme of tolerance assignment

There are some methods for determination of confidence intervals of parameters, state variables, and decision selection criteria (objective functions) of system elements based on engineering dimensional chains calculation. These methods include methods based on limiting values, methods based on intervals calculation, and probability methods.

The closing link tolerance is a separable function if the assembly of components takes place. In general, the closing link tolerance is a nonlinear function of its variables - chain links components tolerances.

A decrease of risks related to the high cost of complex technical systems refinement in serial production is possible due to the adoption of the Robust Estimation methods based on the matching learning algorithms. The Robust Estimation has the following issues that need to be addressed: the problem of improvement of existing mathematical models, and the development of new mathematical models and methods for solving stochastic optimization multi-criteria problems (SOMCP).

It is known that random data triggers the uncertainties during the choice of the metrics in objective functions and estimation of target values (parameters, control variables, or state variables) during SOMCP structuring. Besides, the regularizing algorithms must be used for such type of ill-posed problem solving. This provides the stable (robust) estimates of target values. At the same time, the mathematical models will have robust quality, if they are synthesized with the use of regularizing algorithms.

Up to now, many papers have been devoted to the development of the methods, including the methods for objective functions and estimation of target values under conditions of data parametric uncertainties; multi-criteria identification of mathematical models; optimization and decision-making in the robust designing, improving and intellectual diagnostics of technical and medical-biological systems.

The model of optimization under conditions of uncertain multidisciplinary design, which is described by L. Brevault et al. [1], is aimed at the organization of interdisciplinary connections under uncertainties. The suggested method is based on two levels of optimization and surrogate models to provide the convergence of the optimization problem of the functional ratio of multidisciplinary system connections. The solution search algorithm is based on the iterative construction of the functional connections' surrogate models. Coefficients are processed by a system-level optimizer, while subsystem optimizers process local design variables only. 
The model selection is a fundamental problem, which is widely discussed during the process of data sets analysis. The hierarchical models with uncertainties may not have a solution when classical approaches are used. Bayes approaches could be applied with predictive distribution usage, but they have disadvantages in certain cases.

Other approaches are also described in the literature: predicting the replication of observed data [2]; the theory of estimation rules on common probability spaces and cross-validation [3]; the probabilistic process described by the Kriging surrogate model with Monte Carlo uncertainty modeling in conjunction with the descriptive sampling method [4].

The solution of design and optimization problems is called stable (robust) if it is resistant to the disturbance of input parameters of the model. The design engineer may prefer to use a robust solution for engineering design optimization problems rather than the optimal one to provide system robustness.

Various approaches to this problem exist, including multi-purpose optimization based on a generalization of the class of functions, which allows conducting orientation of the search area in the object space [5]; combined criteria for stochastic optimization [6]; optimization under uncertainties using parallel computing capabilities in various formulations of problems [7]; search for an allowable range in the input parameters, given an acceptable range in the output quantities [8]; a method for quantifying multidimensional interval uncertainties [9]; interdisciplinary automated process optimization based on an optimization strategy designed to overcome various limitations [10].

The following locally stochastic methods (including those, which are based on self-organization) are used as computational methods for solutions synthesis in stochastic optimization problems:

- stochastic quasi-gradient algorithms;

- evolutionary (genetic, immune) algorithms;

- population methods (simulation of motion: migratory birds; ant or bee colonies).

The overview of evolutionary and computational methods, which can be successfully used for stochastic optimization problem solving, is presented in A.P Karpenko monograph [11] and as publications by other authors [12-14].

I. Meniailov et al. proposed a computational method of solutions synthesis of system modification multi-criteria problems in deterministic and stochastic (MVproblems) formulations, which is based on a memetic algorithm [15]. This method combines the method of the convergent neighborhood; the randomized path relinking method; and the evolutionary method with parameters, which are changing from epoch to epoch. These parameters are the real coding operators, fitness, and relaxation functions. This approach provides an effective robust estimation of target values when input data are a priori and parametric uncertainties ones. Also, this approach reduces the informational complexity of the method.

Analysis of existing literature shows that some mathematical issues appear in the process of the development of solutions synthesis methods of multi-criteria problems of mathematical model identification, optimization, and decisionmaking, especially in the cases of the a priori uncertain data. These issues include: 
- decision maker (DM) preferences system forming, i.e. forming of the generalized (the scalar convolutions) objective functions, the limitations system, and the correctness set;

- structuring of the regularizing algorithms of quasi-solutions synthesis;

- the high computational complexity of the defined methods.

Only a few interactive computer systems for decision-making support (CSDMS), which provide robust optimal design feature, exist in the world. These include "Dakota, A Multilevel Parallel Object-Oriented Framework for Design Optimization, Parameter Estimation, Uncertainty Quantification, and Sensitivity Analysis" [16], "IOSO Technology, Robust design optimization" [17], "ESTECO, modeFRONTIER" [18, 19], "Dassault Systems, Isight and Fiper" [20], "DYNARDO, optiSLang" [21], "NUMECA International, FineDesign3D" [22], "Concepts NREC's, Agile Engineering Design System" [23], "AxSTREAM Software" [24], "Propulsion Diagnostic Method Evaluation Strategy (ProDiMES)" [25], and others.

These systems have the following disadvantages: high cost, inability to resolve stochastic optimization multi-criteria problems in MV-formulation (i.e. inverse and direct problems in engineering dimensional chains calculation).

This paper is dedicated to new methodology of non-linear robust estimation for the solutions synthesis of inverse and direct engineering dimensional chains calculation problems under the conditions of a priori and parametric uncertainties. It is shown that this problem can be transformed into multi-criteria problems of stochastic optimization with mixed conditions (to MV-problem). The suggested methodology allows us to search for rational solutions of system modification multi-criteria problems $[26,27]$ presented in deterministic and stochastic (MVproblem) formulations. This is done through the development of a hierarchical two-level decisions synthesis scheme, which includes:

- inverse determination of the unknown equations governing the variation of measured field quantities of given physical problem - shape identification of robust meta-models or surrogate models (formal mathematical models in the form of regression equations);

- inverse determination of size(s) and shape(s) of the domain - effective robust sought values estimations of unknown quantities are carried out under a priori and parametric data uncertainties.

Results of an inverse and direct problem in engineering dimensional chains calculation for Two-stage axial compressors are resolved by CSDMS "ROD\&IDS". The result is presented below.

\section{PROBLEM STATEMENT}

\section{Problem statement and a method for selection of functions and estimation of unknown variables in multi-objective problems with the a priori uncer- tainties data}

Let us consider the problem statement, methodology and results of the solution of Direct Multidisciplinary Problems in Engineering Dimensional Chains Calculation under Uncertainties in nonlinear statement (multi-criteria problems of stochastic optimization with mixed conditions - MV-problems). 
The following data are known, presented in a formalized form: structure, functioning model (mathematical model, boundary conditions), properties and general characteristics of the research object, basic requirements for its tactical, technical and economic criteria; the class of admissible controls (methods and devices implementing them).

Let it be known a set of alternatives - learning selection that contains values and confidence intervals of subsystem (functional unit) parameters and control variables. Additionally, the values of mathematical expectations and confidence intervals of decision criteria (objective functions) values are known or phase variables of the system (subsystem) or process under consideration are given. These values are set either by the decision-maker based on his experience or directives or are known based on the results obtained using the measurement system.

So, it is necessary to determine the set of mathematical expectations and confidence intervals of subsystem (functional unit) control variables (model parameters - in the case of an identification problem) and the corresponding values of mathematical expectations and confidence intervals of decision criteria (objective functions) values or phase variables of the system (subsystem) or process under consideration. At the same time, the last found values should be close to the given values of objective functions or phase variables (mathematical expectations and confidence intervals) for the selected metrics.

The Direct Multidisciplinary Problems in Engineering Dimensional Chains Calculation under Uncertainties in nonlinear statement refer to inverse boundary value problems in a stochastic formulation with restrictions on design and operating parameters, phase and control variables.

We will consider the solutions synthesis of the problem as a control process that is based on the concept of invariant control by introducing into the computing system a compensating connection with perturbations (input data and computing errors).

Consider $X^{0}$ as a vector of random variables of $M$ dimensions (the model parameters, control variables, state variables); and $F^{0}$ as a vector of random variables of $I$ dimensions (measurement data, objective functions). The values $F^{0}$ can be found using the initial mathematical model (IMM) of the investigation subject reflected in the form of $F^{0}=F\left(X^{0}\right)$, where $F$ is a vector function.

Let us define the projections of $X^{0}$ and $F^{0}$ as the random variables following a normal distribution with given mathematical expectations, standard deviations, and correlation matrices. This allows considering $X^{0}$ and $F^{0}$ as systems of several random variables with the multidimensional normal distribution.

Following Kolmogorov's concept of power averages [28], we will use Student's statistics as a criterion for testing the equality of centers of distributions hypothesis for representative samples of two multidimensional general populations; and we will use the multidimensional analog of Romanovsky criterion [29-31] for testing the equality hypothesis of covariance matrices $R o$ :

$$
t=\sqrt{\frac{n_{\alpha}}{2} M D^{2}}
$$


where $n_{\alpha}$ is the dimension of samples from the general populations; $M D$ is Mahalanobis distance.

$$
R o=\frac{\left|\chi^{2}-k\right|}{\sqrt{2 k}}, k=n_{\alpha}-3
$$

where $\chi^{2}=\frac{n_{\alpha}}{N}\left(\sigma^{0}\right)^{T} R \sigma^{0}$ is the multidimensional analog of Pearson's chisquared test; $N$ is a dimension of $X^{0}$ (or $F^{0}$ );

$$
\sigma^{0}=\left\{\frac{\sigma_{n}}{\sigma_{n}^{*}}\right\}, n=1 . . N ;
$$

$\sigma_{n}, \sigma_{n}^{*}$ are standard deviations of variables $x_{n} \in X^{0} \quad(*-$ given values); $R$ is a correlation matrix.

Let us define the log-likelihood function. The final form of the scalar convolution for decision-making problems with (1-2) looks like:

$$
L\left(\hat{X} / t_{F}, R o_{F}\right)=\frac{1}{2}\left(t_{F}^{2}+R o_{F}+t_{X}^{2}+R o_{X}\right)+C_{L} .
$$

\section{Scalar convolutions for the multi-objective problems with the a priori uncertainties data}

Further, let us assume that, $R_{X}=R_{F}=E$, where $R_{X}$ and $R_{F}$ are the correlation matrices. In this case, the following scalar convolution of objective functions in MV-problems is applied:

$$
\begin{aligned}
& E=\frac{1}{2 I} \sum_{i=1}^{I}\left\{f_{f i t}\left[\left(\mu_{i}\left(f_{i}^{*}\right) \frac{\Delta_{f_{i}}}{f_{i}^{*}}\right)^{2}\left(1+\sigma_{f_{i}}^{0}\right)^{-2}\right]+\beta_{f} f_{f i t}\left(\frac{\left|\chi_{f_{i}}^{2}-k\right|}{\sqrt{2 k}}\right)\right\}+ \\
& +\gamma \frac{1}{2 M} \sum_{m=1}^{M}\left\{f_{f i t}\left[\left(\mu_{m}\left(x_{m}^{*}\right) \frac{\Delta_{x m}}{x_{m}^{*}}\right)^{2}\left(1+\sigma_{x m}^{0}\right)^{-2}\right]+\beta_{x} f_{f i t}\left(\frac{\left|\chi_{x m}^{2}-k\right|}{\sqrt{2 k}}\right)\right\},
\end{aligned}
$$

where

$$
\begin{gathered}
\Delta_{f_{i}}=M_{\alpha}\left[f_{i}\right]-f_{i}^{*}, \chi_{f_{i}}^{2}=n_{\alpha} \frac{M_{\alpha}\left[\left(f_{i}-M_{\alpha}\left[f_{i}\right]\right)^{2}\right]}{\left(\sigma_{f_{i}}^{*}\right)^{2}} ; \sigma_{f_{i}}^{\circ}=\left\{\frac{\sigma_{f_{i}}}{\sigma_{f_{i}}^{*}}\right\} ; \\
\frac{\left|\chi_{f_{i}}^{2}-k\right|}{\sqrt{2 k}}=\frac{n_{\alpha}}{\sqrt{2\left(n_{\alpha}-3\right)}\left|\left(\sigma_{f_{i}}^{\circ}\right)^{2}-1+\frac{3}{n_{\alpha}}\right| ;} \\
\Delta_{x m}=M_{\alpha}\left[x_{m}\right]-x_{m}^{*}, \chi_{x m}^{2}=n_{\alpha} \frac{M_{\alpha}\left[\left(x_{m}-M_{\alpha}\left[x_{m}\right]\right)^{2}\right]}{\left(\sigma_{m}^{*}\right)^{2}} ; \sigma_{x m}^{\circ}=\left\{\frac{\sigma_{x m}}{\sigma_{x m}^{*}}\right\} ; \\
\frac{\left|\chi_{x m}^{2}-k\right|}{\sqrt{2 k}}=\frac{n_{\alpha}}{\sqrt{2\left(n_{\alpha}-3\right)}\left|\left(\sigma_{x m}^{\circ}\right)^{2}-1+\frac{3}{n_{\alpha}}\right|,}
\end{gathered}
$$


$x_{m}^{*}, \sigma_{m}^{*}$ are the values of mathematical expectation and standard deviation of $x_{m}$ variable for the prototype; $\sigma_{x m}$ is standard deviation value of $x_{m} \in X^{0}$ variable; $f_{i}^{*}, \sigma_{f_{i}}^{*}$ are the values of mathematical expectation and standard deviation of $f_{i}$ decision selection criterion for the prototype; $\sigma_{f_{i}}$ is standard deviation value of $f_{i} \in F^{0}$ decision selection criterion; $f_{f i t}$ is a fitness function (FF); $f_{f i t}(d)=1-\exp (-C d), C>0$ (it has been selected based on the condition that initial value of $E_{a v}^{(1)}$ was $\left.E_{a v}^{(1)}<1\right)$, where $d$ is an argument of FF $(d>0)$; $\mu_{i}\left(f_{i}^{*}\right), \mu_{m}\left(x_{m}^{*}\right)$ are membership functions; $\gamma$ is a parameter of regularization (if $\gamma=0$ this is epy identification, else if $\gamma=1$ this is optimization); $\beta_{f}, \beta_{x}$ are parameters of robustness.

Hence, the problem of $\hat{X}=\left(M\left[X^{0}\right], \sigma_{X}^{0}\right)$ non-linear robust estimation can be transformed to SOMCP with mixed conditions (to MV-problem in our case). According to the principle of maximum likelihood [32] (M-estimate), the quasisolution of this problem is the following:

$$
\hat{X}=\underset{\hat{X} \in D_{X}}{\arg \inf } E\left(\hat{X} / t_{F}, R o_{F}\right),
$$

where $D_{X}$ is a correctness set, which is defined by the decision maker's system of preferences in the general case. It was assumed in this case that $D_{X}$ is a convex set.

\section{THE NEW METHODS NON-LINEAR ROBUST ESTIMATION FOR THE SOLUTIONS SYNTHESIS OF INVERSE AND DIRECT MULTIDISCIPLINARY PROBLEMS IN ENGINEERING DIMENSIONAL CHAINS CALCULATION BASED ON DISCRETE ANALOG DATA}

As a result of the decomposition of the methodology to solve the main problem $(3,4)$, it decomposes into a sequence of interrelated methods, in particular:

- Input data preparation: input data preliminary normalization methods. Data of alternatives (samplings) are used as input data: design values and operational parameters, control and phase variables, decision selection criteria (objective functions). The samplings are formed using either the solutions in the deterministic formulation of the direct analysis problem or the results of discrete analog data experimental research.

- Methods of inverse determination of the unknown equations governing the variation of measured field quantities of given physical problem - shape identification of robust meta-models or surrogate models (formal mathematical models in the form of regression equations). The methods of approximation of vector functions of vector variables based on the application of a trainable artificial neural network (ANN), which are multilayer feedforward ones and radial-basis ANN. The training of ANN is carried out by a stochastic approximation method based on the conjugate gradients ravine method [33] together with the bee colonies 
simulation, in which the scalar convolution of objective functions (3) with $\gamma=0$ is used for rational decision selection. The proposed implementation allows us to obtain effective stable (robust) estimates of the neural network model parameters under the condition of input a priori and parametric uncertainties. It provides a robust meta-models synthesis and the data approximation accuracy, which is sufficient in system improvement problems. Application of the proposed methods avoids the appearance of false ravines or valleys on response surfaces in case of gross errors in the input data.

- Graphical tools for the 3D-representation of meta-models.

- Methods of meta-model variables informativeness (importance) estimations (taking into account the pair correlation and the accuracy of variables measurement) [34]. In particular, the solutions of controlled variables set synthesis for systems designing or failure diagnostics under conditions of a priori and parametric uncertainties of input data may be obtained on the base of the received results.

- Methods for solving the problem of systems and processes state classification on the base of multilayer feedforward and radial-basis ANN application with the usage of the monitoring data of controlled variables [35].

- Solutions synthesis of system modification multi-criteria problems in deterministic and stochastic (MV-problem) formulations [15, 33].

The solution of the inverse problem of engineering dimensional chains calculation/Monte Carlo analysis (MCA) is found for the prototype at the first stage: the estimation of confidence intervals of decision selection criteria (objective functions) mean values at the given confidence intervals of subsystems control variables (functional elements) mean values.

The quasi-solutions synthesis of this problem is carried out by regularization of the smoothing functional minimum search in the form of objective functions scalar convolution (1) with. The comparative analysis of various systems production technologies may be carried out on the base of the obtained results [15].

Solutions synthesis of the direct problem of engineering dimensional chains calculation - system modification problem quasi-solutions in deterministic and stochastic (MV-problem) formulations is carried out by the regularization method at the second stage. The objective functions scalar convolution (1) was used as the smoothing function [15]. The computational method based on meme's algorithm is applied. It includes the parameters changing from epoch to epoch such as the operators of real coding, the fitness and relaxation functions, and also the method of the convergent neighborhood and the randomized path relinking method.

This approach provides an effective robust estimation of target values when input data are a priori and parametric uncertainties ones. Also, this approach reduces the informational complexity of the quasi-solutions synthesis method.

Thus, the direct problem solution of engineering dimensional chains calculation is solved by the probabilistic method (2). Mathematical expectations and confidence intervals of subsystems control variables (functional elements) are found according to the given values of mathematical expectations and the decision selection criteria confidence intervals (of the objective functions). Also, they could be found according to phase variables of the systems (subsystems). 


\section{NEW MEMETIC ALGORITHM OF THE STOCHASTIC OPTIMIZATION PROBLEM WITH MIXED CONDITIONS}

The quasi-solution of this problem (normal solution) may be find by the regularization method [32]. Quasi-solutions synthesis of system modification multicriteria problems in deterministic and stochastic (MV-problem) formulations is carried out by the computational method based on memes algorithm.

Let us define an evolutionary method (EM) as a classical genetic algorithm (GA) modification with the parameters, which are changing from epoch to epoch. This paper presents features which distinguish the suggested EM from classical GA.

The real coded crossover operator that simulates the binary one is used [11]. Mikhalevich non-uniform mutation operator is used as the real coded mutation operator, which relates to a class of nonstationary mutators.

After crossover operations and mutation, the most adapted individual is selected and put to the set of individuals intended for the next epoch of the algorithm. The most adapted individual is the individual, the selection criteria scalar convolution values of which are the most acceptable.

It is known that clustering is one of the means for the EM convergence rate to increase. Decremental Neighborhood Method (DNM), which realizes the idea of clustering [15], has been developed to improve the convergence rate and accuracy of the extremum finding.

The suggested memetic algorithm is several times less complex in terms of the information and time complexities compared to the classical GA, because of combining parameters changing from epoch to epoch such as the operators of real coding, the fitness and relaxation functions and also the method of the convergent neighborhood and the randomized path relinking method.

\section{NUMERICAL TESTS}

The "ROD\&IDS" interactive computer system for decision-making support was developed. It implements the foregoing methodology.

As an example, let us consider the results of an inverse and direct problem in engineering dimensional chains calculation for a two-stage axial compressor under conditions when input data is stochastic.

The aerodynamic design of the compressor two axial stages was fulfilled for gas-turbine drive power increasing from 8 to $10 \mathrm{MW}$. The "Axial" software (Copyright (C) 1998-2017. Concepts NREC LLC) [23] was used during the stages calculations basing on the average radius parameters. The problems of these stages efficiency increasing (without gas-dynamic stability reducing) at the design values of inlet mass flow rate and rotational speed was solved by the application of "ROD\&IDS".

The compressor efficiency maximum search was carried out with following elements changes of blades rows of the first and second compressor stages: the gas path tip radius (6 variables), stagger angles (4 variables), entry and exit geometrical angles ( 8 variables) and the cascade solidity (4 variables). For the inlet guide vanes, only the gas path was changed. Experimental sampling was formed 
by the change of the gas path radius (within $\pm 2 \mathrm{~mm}$ ), geometrical angles of blades airfoils (within \pm 2 degrees), and the blades row chord/pitch ratios (within $\pm 5 \%$ ). Approximation of the lines of constant referred speed, beginning from surge line to choke measure is used to adequately describe the effect of varying parameters on the stages map. The computation of inlet mass flow rate values between surge and choke was performed by "Axial" macros. This way, the following quantity of state variables under control was selected: 22 geometric parameters, 1 regime parameter (an inlet mass flow rate), and 450 points characterizing the experimental sampling size.

The following parameters were selected as objective functions:

$-\alpha_{\text {out }}$ is flow outlet angle;

- $\pi^{*}$ is compressor total pressure ratio at the design inlet mass flow rate value;

- $\eta^{*}$ is adiabatic efficiency calculated according to total parameters values at the design inlet mass flow rate value;

$-\pi_{\text {stall }}^{*}$ is total pressure ratio on surge line;

- $G_{\text {choke }}$ is the choke inlet mass flow rate value;

- form-parameter is the parameter of response surface form corresponding to the objective function selected at the design inlet mass flow rate value.

Further, the robust neural network models in the form of radial-basis ANNs were used as meta-models of the systems.

Optimization was carried out based on the design inlet mass flow rate values in deterministic and stochastic formulations.

Computational results in the deterministic formulation are presented in Fig. 2 and Table 1, where normalized values are: $G^{0}=G / G_{p, 0}, \pi^{0}=\pi^{*} / \pi_{p, 0}^{*}$, $\eta^{0}=\eta^{*} / \eta_{p, 0}^{*}, \Delta \eta^{*}=\eta^{*}-\eta_{p, 0}^{*}$ is the efficiency change at the design inlet mass flow rate value in comparison with the prototype, and $\Delta K_{y}$ is gas-dynamic stability margin.

The first deterministic formulation of the optimization problem is selected in such a way that the efficiency maximum at the design inlet mass flow rate value is provided along with the required level of total pressure ratio. As a result, the efficiency increment by $0,41 \%$ in comparison with the prototype was achieved at the design inlet mass flow rate value (MC_2_ (v.2.1) results). The efficiency maximum along the line of constant referred speed is close to the design point. At the same time, the gas-dynamic stability margin increased from $12,6 \%$ to $14,44 \%$.

The second deterministic formulation of the optimization problem (MC_2 (v.4.4) results) is implemented to examine how much it is possible to vary the limitations in the optimization problem. For example, let us consider the problem of obtaining a greater efficiency maximum with a more steep behavior of line of constant referred speed in comparison with the prototype. As shown in Fig. 2, the line of constant referred speed with more steep behavior provides a higher level of gas-dynamic stability margin (13,8\% in comparison with prototype's $12,16 \%)$ and high maximal efficiency value is provided too. The difference of this optimization from previous decisions lies in the fact that the compressor efficiency is $1,45 \%$ less than the prototype's one at the design inlet mass flow rate value. 

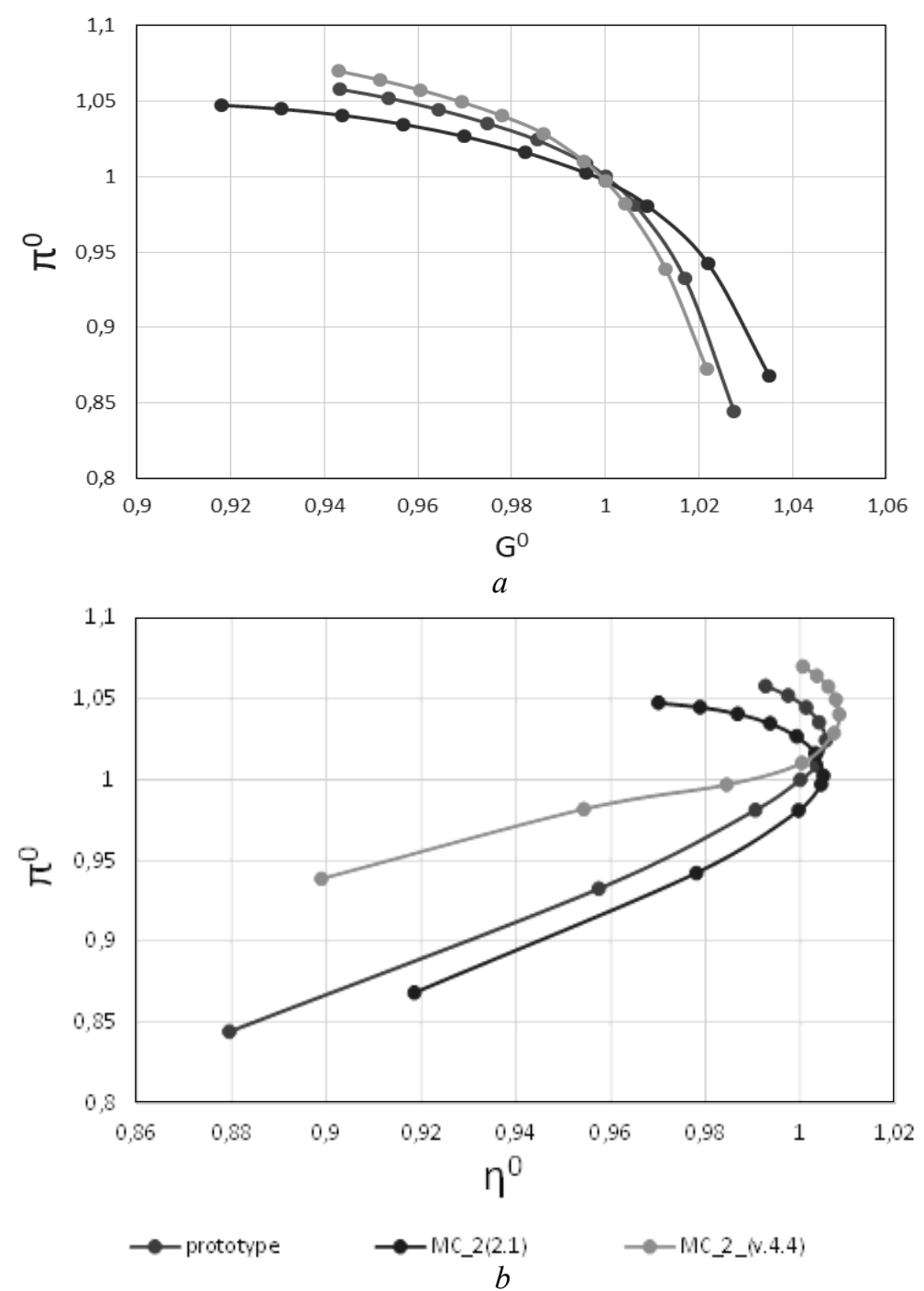

Fig. 2. Performances of the prototype and compressors optimal versions: $a-\left[G^{0}, \pi^{0}\right]$ relation; $b-\left[\eta^{0}, \pi^{0}\right]$ relation

Thus, according to the provided example, it was shown that obtaining such blade rows geometry is possible. This solution can meet the requirements of the compressor performances made by a design engineer.

As an example, the calculations intended to provide efficiency maximum value at the designed inlet mass flow rate and efficiency maximum along the line of constant referred speed were performed. These calculations meet the required level of the total pressure ratio (the same as the prototype's one). Implementation of additional limitations to the objective functions gives the possibility to get more or less steep behavior of the two-stage compressor line of constant referred speed in comparison with the prototype.

Let us consider the manufacturing of a product series consisting of 100 copies. We chose a prototype, optimized it in a traditional deterministic formulation. We enhanced of the efficiency for compressor optimal version at deterministic formulation $\Delta \eta_{d}^{*}=0,406 \%$ in comparison with the prototype (see in Table 1). 
Ta b l e 1. Comparison of objective functions values for compressors versions

\begin{tabular}{|c|c|c|c|}
\hline Values/Variants & $\Delta \eta_{d}^{*}, \mathbf{\%}$ & $\Delta \eta_{\max }^{*}, \mathbf{\%}$ & $\Delta K_{\text {stall }}, \mathbf{\%}$ \\
\hline Prototype & 0 & 0,494 & 12,157 \\
\hline MC_2_(v.2.1)/ deterministic formulation & 0,406 & 0,449 & 14,444 \\
\hline MC_2(v.4.4)/deterministic formulation & $-1,448$ & 0,756 & 13,80 \\
\hline
\end{tabular}

Further, taking as a basis the calculated parameters of this optimal version, we will make 100 copies of products. To conclude that the products comply with the technical specifications, we will evaluate the results of numerical modeling of work of 100 copies of products in accordance with the methodology presented in the article.

Mathematical expectation, confidence intervals of regime parameters mean values, and control variables, which are the prototype data, are known (the first row in Tables 2 and 3). In Table $2-\Delta_{x_{m}}^{0}=\frac{\Delta x_{m}}{x_{m, \max }} \cdot 100$ is the accuracy class of regime parameters and control variables, $x_{m, \max }$ parameter is the maximum value in the learning sample.

The stochastic formulation of the optimization problem is selected in such a way that the maximal level of efficiency mathematical expectation at the design inlet mass flow rate value and at the required level of objective functions mathematical expectations and confidence intervals would be provided in the product line.

Solving the inverse problem of engineering dimensional chains calculation/Monte Carlo analysis (MCA) was carried out for the prototype on the first stage. In other words, estimation of confidence intervals of decision selection criteria (objective functions) mean values were carried out under given confidence intervals of subsystems control variables mean values (functional elements). MCA results are presented in Tables 3 and 4. Table 3 shows that the confidence intervals of objective functions mean values increased in comparison with assumed measurement precision. At the same time, the values of mathematical expectations of objective functions were reduced for the considered compressor versions (see Table 4). These MCA results are typical for the results obtained in the deterministic statement.

System modification quasi-solutions synthesis in the stochastic formulation (MV-problem) is carried out on the second stage in order searching the mathematical expectations and confidence intervals of subsystem (functional unit) control variables and the corresponding values of mathematical expectations and confidence intervals of decision criteria (objective functions) values or phase variables of the system (subsystem) or process under consideration at the design inlet mass flow rate value that is close to the given values for the selected metrics.

Overall results of decisions synthesis of modification problems are presented in the stochastic formulation, in other words, the confidence intervals of regime parameters and control variables mean values are presented in Tables 2-4. A comparison of mathematical expectations of objective function values is presented in Tables 2-4 too. 
Table 2. Confidence intervals of regime parameters and control variables mean values

\begin{tabular}{|c|c|c|c|c|}
\hline Values/variants & $\Delta^{0} G, \begin{array}{c}\Delta^{0} \text { of gas path } \\
\text { duct radii on the } \\
\text { periphery, \% }\end{array}$ & $\begin{array}{c}\Delta^{0} \text { of blades rows } \\
\text { geometrical angles, } \\
\text { \% }\end{array}$ & $\begin{array}{c}\Delta^{0} \text { of the } \\
\text { cascade } \\
\text { solidity, \% }\end{array}$ \\
\hline Prototype/given values & $\pm 0,05$ & $\pm 5,0$ & $\pm 2,5$ & $\pm 1,0$ \\
\hline $\begin{array}{c}\text { MC_2_(v.2.1)/deterministic } \\
\text { formulation/given values }\end{array}$ & $\pm 0,05$ & $\pm 5,0$ & $\pm 2,5$ & $\pm 1,0$ \\
\hline $\begin{array}{c}\text { MC_2_(v.2.1)/stochastic } \\
\text { formulation/calculation } \\
\text { results }\end{array}$ & $\pm 0,04$ & $\pm 4,0$ & $\pm 2,0$ & $\pm 0,8$ \\
\hline
\end{tabular}

Ta b le 3. Confidence intervals of objective functions mean values

\begin{tabular}{|c|c|c|c|c|c|c|}
\hline $\begin{array}{c}\text { Values/ } \\
\text { variants }\end{array}$ & $\begin{array}{c}\Delta \alpha_{\text {out }}, \\
\text { degrees }\end{array}$ & $\Delta \pi_{d}^{*}$ & $\Delta \eta_{d}^{*}, \%$ & $\Delta \pi_{\text {stall }}^{*}$ & $\begin{array}{c}\Delta G_{\text {choke }}, \\
\mathbf{~ k g / s}\end{array}$ & $\begin{array}{c}\Delta \text { Form- } \\
\text { parameter }\end{array}$ \\
\hline $\begin{array}{c}\text { Precision } \\
\text { of Measurements }\end{array}$ & $\pm 0,2367$ & $\pm 0,0121$ & $\pm 0,47$ & $\pm 0,0122$ & $\pm 0,2680$ & $\pm 0,0004$ \\
\hline $\begin{array}{c}\text { Prototype/ } \\
\text { Monte Carlo analysis }\end{array}$ & $\pm 0,0882$ & $\pm 0,0180$ & $\pm 0,58$ & $\pm 0,0053$ & $\pm 0,0575$ & $\pm 0,0068$ \\
\hline $\begin{array}{c}\text { MC_2_(v.2.1)/ } \\
\text { deterministic } \\
\text { formulation/ } \\
\text { Monte Carlo analysis }\end{array}$ & $\pm 0,1626$ & $\pm 0,0660$ & $\pm 2,49$ & $\pm 0,0049$ & $\pm 0,0547$ & $\pm 0,0216$ \\
\hline $\begin{array}{c}\text { MC_2_(v.2.1)/ } \\
\text { stochastic } \\
\text { formulation/desired } \\
\text { values }\end{array}$ & $\pm 0,0900$ & $\pm 0,0120$ & $\pm 0,50$ & $\pm 0,0050$ & $\pm 0,0600$ & $\pm 0,0070$ \\
\hline $\begin{array}{c}\text { MC_2_(v.2.1)/ } \\
\text { stochastic } \\
\text { formulation/ } \\
\text { calculation results }\end{array}$ & $\pm 0,0830$ & $\pm 0,0126$ & $\pm 0,41$ & $\pm 0,0055$ & $\pm 0,0508$ & $\pm 0,0053$ \\
\hline
\end{tabular}

Table 4. Comparison of mathematical expectations of objective functions values for compressors versions

\begin{tabular}{|c|c|c|c|c|c|}
\hline Values/versions & $\begin{array}{c}\Delta \alpha_{\text {out }}, \\
\text { degrees }\end{array}$ & $\Delta \pi_{d}^{*}$ & $\Delta \eta_{d}^{*}, \mathbf{\%}$ & $\Delta \pi_{\text {stall }}^{*}$ & $\begin{array}{c}\Delta G_{\text {choke }}, \\
\mathbf{k g} / \mathbf{s}\end{array}$ \\
\hline Prototype/Monte Carlo analysis & $-0,03$ & $-0,015$ & $-0,58$ & $-0,011$ & 0,009 \\
\hline $\begin{array}{c}\text { MC_2_(v.2.1)/deterministic } \\
\text { formulation/Monte Carlo analysis }\end{array}$ & $-0,20$ & $-0,083$ & $-2,49$ & 0,019 & 0,053 \\
\hline $\begin{array}{c}\text { MC_2_(v.2.1)/stochastic } \\
\text { formulation/calculation results }\end{array}$ & 0,02 & 0,016 & 0,24 & $-0,009$ & 0,603 \\
\hline
\end{tabular}

The result presented in Table 4 shows that the efficiency mathematical expectation value $\Delta \eta_{d}^{*}$ for compressor optimal version at deterministic formulation decreased by $(2,49-0,58) \%=1,91 \%$ in comparison with the prototype data obtained by MCA method. The result presented in Table 3 shows that the efficiency confidence interval value for compressor optimal version at deterministic formu- 
lation enhanced by $(2,49-0,58) \%=1,91 \%$ in comparison with the prototype data obtained by MCA method.

This is the main result of the research, confirming what said earlier that a good exact solution of the inverse problem in a deterministic formulation (optimization problem) in practice in mass production, as a rule, leads to a large scatter of the values of the integral characteristics of products.

The result presented in Table 4 shows that the efficiency mathematical expectation value $\Delta \eta_{d}^{*}$ for compressor optimal version at stochastic formulation is enhanced by $(0,24+0,58) \%=0,82 \%$ in comparison with prototype. It should be noted, that at the same time saved desired confidence intervals average values of objective functions (see the last row in Table 3). But this could be achieved by $20 \%$ enhancement of compressor elements manufacturing accuracy (see the last row in Table 2).

Also, there is a significant difference in the mathematical expectations, values of the control variables, which were obtained by problem-solving in deterministic and stochastic formulations.

Here is a justification for the need implementation of the concept and developed by us methodology of robust estimation based on the synthesis of robust surrogate models and solutions to multidisciplinary MV-problems in mass manufacturing of products. The use of our developments in mass manufacturing of products will reduce the percentage of rejects.

The sought quantities estimations in the result of solving of modification problem in the stochastic formulation are the effective and stable (robust) ones.

\section{CONCLUSIONS}

The new methodology of non-linear robust estimation for the solutions synthesis of inverse and direct multidisciplinary problems in engineering dimensional chains calculation under conditions of a priori and parametric uncertainties was developed. It is shown that this problem as a inverse boundary value problems in a stochastic formulation can be transformed into multi-criteria problems of stochastic optimization with mixed conditions (MV-problems). The methodology allows us to obtain the rational solutions of system modification multi-criteria problems in deterministic and stochastic (MV-problem) formulations. It can be achieved through hierarchical two-level decisions synthesis scheme development, which includes:

- inverse determination of the unknown equations governing the variation of measured field quantities of given physical problem - shape identification of robust meta-models or surrogate models (formal mathematical models in the form of regression equations);

- inverse determination of size(s) and shape(s) of the domain - effective robust sought values estimations of unknown quantities are carried out under a priori and parametric data uncertainties.

The results of solving inverse and direct problems in engineering dimensional chains calculation under the conditions where input data are stochastic for two-stage axial compressors were obtained with the usage of "ROD\&IDS" and provided as an example. 
Based on the analysis of numerical simulation results shown, that a good exact solution of the inverse problem in a deterministic formulation (optimization problem) in practice in mass production, as a rule, leads to a large scatter of the values of the integral characteristics of products.

Application in practice of the concept and developed by us methodology of robust estimations, based on the synthesis of robust surrogate models and solutions to multidisciplinary MV-problems, in mass manufacturing of products will reduce the percentage of rejects.

The developed interactive computer systems for decision-making support "ROD\&IDS" can be applied to various fields of science, medicine, and technology. Particularly, this software may be used by the wide range of specialists, who work on the issues of robust meta-models' design (formal mathematical models in the form of regression equations), as well as on the issues of optimization and decision-making in the process of robust design, improving and intellectual diagnostics of technical and medical-biological systems, ecology, the activities of banks, insurance, and audit companies etc.

\section{REFERENCES}

1. L. Brevault, M. Balesdent, R. Le Riche, and N. Berend, "Multi-level hierarchical MDO formulation with functional coupling satisfaction under uncertainty, application to sounding rocket design", in Proceedings of the 11th World Congress on Structural and Multidisciplinary Optimisation, 7-12 June 2015, Sydney, Australia.

2. A.E. Gelfand and S.K. Ghosh, "Model choice: A minimum posterior predictive loss approach", Biometrika, 85 (1), pp.1-11, 1998.

3. T. Gneiting and A.E. Raftery, "Strictly proper scoring rules, prediction, and estimation", American Statistical Association Journal of the American Statistical Association, 102(477), pp. 359-378, 2007.

4. S. Lee, D. Rhee, and K. Yee, "Optimal arrangement of the film cooling holes considering the manufacturing tolerance for high pressure turbine nozzle", in Proceedings of ASME Turbo Expo 2016: Turbomachinery Technical Conference and Exposition, 13-17 June 2006, Seoul, South Korea.

5. T. Erfani and S.V. Utyuzhnikov, "Control of robust design in multiobjective optimization under uncertainties", Structural and Multidisciplinary Optimization, 45(2), pp. 247-256, Feb. 2012.

6. I.N. Egorov and G.V. Kretinin, "Optimization of gas turbine engine elements by probability criteria", in Proceedings of ASME 1993 International Gas Turbine and Aeroengine Congress and Exposition, 24-27 May 1993, Cincinnati, OH.

7. A.A. Giunta, M.S. Eldred, L.P. Swiler, T.G. Trucano, and S.F. Wojtkiewicz, "Perspectives on optimization under uncertainty: algorithms and applications", in Proceedings of 10th AIAA/ISSMO Multidisciplinary Analysis and Optimization Conference, 30 Aug. -1 Sept. 2004, Albany, NY.

8. K.K. Bodla, J.Y. Murthy, and S.V. Garimella, "Optimization under uncertainty for electronics cooling design applications", in Proceedings of 13th InterSociety Conference on Thermal and Thermomechanical Phenomena in Electronic Systems, 30 May -1 June 2012, San Diego, CA, pp. 1191-1201.

9. M. Broggi, M. Faes, E. Patelli, Y. Govers, D. Moens, and M. Beer, "Comparison of Bayesian and interval uncertainty quantification: Application to the AIRMOD test structure", in Proceedings of 2017 IEEE Symposium Series on Computational Intelligence (SSCI), 27 Nov. -1 Dec. 2017, Honolulu, HI, pp.1-8. 
10. A.-L. Aulich and D. Goerke, "Multidisciplinary automated optimization strategy on a counter rotating fan", in Proceedings of ASME Turbo Expo 2013: Turbine Technical Conference and Exposition GT2013, 3-7 June 2013, San Antonio, TX. (ASME paper GT2013-94259)

11. A.P. Karpenko, Modern algorithms. Algorithms inspired by nature: study guide. Moscow: MSTU Publishing House N.E. Bauman, 2014.

12. C. Blum, M.J.B. Aguilera, A. Roli, and M. Sampels (Eds.), Hybrid Metaheuristics: An Emerging Approach to Optimization. Berlin: Springer-Verlag, 2008.

13. K. Deb, Multi-objective optimization using evolutionary algorithms. Chichester, UK: Wiley, 2001.

14. X.S. Yang, Nature-inspired Metaheuristic Algorithms. Frome (UK): Luniver Press, 2010.

15. I. Meniailov, O. Khustochka, K. Ugryumova, S. Chernysh, S. Yepifanov, and M. Ugryumov, "Mathematical models and methods of effective estimation in multiobjective optimization problems under uncertainties", in Advances in Structural and Multidisciplinary Optimization: Proceedings of WCSMO12, 5-9 June 2017, Braunschweig, Germany. SpringerLink, 2018.

16. National priorities. Featured at Sandia. Albuquerque, NM: Sandia, LLC. Accessed on: June 2, 2019. [Online]. Available: www.sandia.gov

17. High efficiency IOSO design optimization software. Moscow, Russia: Sigma Technology. Accessed on: June 2, 2019. [Online]. Available: www.iosotech.com

18. Robust Design \& Reliability. Trieste, Italy: ESTECO SpA. Accessed on: June 2, 2019. [Online]. Available: http://www.esteco.com/modefrontier/robust-designreliability/

19. ISIGHT \& The Simulia execution engine. Process automation and design exploration. Trieste, Italy: ESTECO SpA. Accessed on: June 2, 2019. [Online]. Available: https://www.3ds.com/products-services/simulia/products/isight-simulia-executionengine/

20. TOSCA Fluid. Design concepts and CFD optimization for fluid flow. VélizyVillacoublay, France: Dassault Systèmes. Accessed on: June 2, 2019. [Online]. Available: www.3ds.com/products-services/simulia/products/tosca/fluid/

21. Optimization and robust design optiSLang. Moscow, Russia: CADFEM-CIS. Accessed on: June 2, 2019. [Online]. Available: www.cadfem-cis.ru/products/ additional/ optislang/

22. NUMECA International, FineDesign3D. Brussels, Belgium: NUMECA International. Accessed on: June 2, 2019. [Online]. Available: http://www.numeca.com/home

23. The Complete Software Solution - From Art to Part . White River Junction, VT: Concepts NREC. Accessed on: June 2, 2019. [Online]. Available: http://www. conceptsnrec.com/solutions/software

24. SoftInWay Inc. «AxSTREAM» Software Platform. Burlington, MA: SoftInWay Inc. Accessed on: June 2, 2019. [Online]. Available: http://www.softinway.com/software/

25. Intelligent Control and Autonomy Branch. Propulsion Diagnostic Method Evaluation Strategy (ProDiMES). Cleveland, OH: NASA Glenn Research Center. Accessed on: June 2, 2019. [Online]. Available: https://www.grc.nasa.gov/www/cdtb/software/ehmbenchmark.html

26. M.L. Ugryumov, A.A. Tronchuk, V.E. Afanasjevska, and A.V. Myenyaylov, "Gas turbine engine elements systematic improvement on the base of inverse problem concept by stochastic optimization methods", in Proceedings of the 20-th ISABE Conference, 12-16 Sept. 2011, Gothenburg, Sweden. (ISABE Paper no. 2011-1255).

27. M.L. Ugryumov, A.A. Tronchuk, V.E. Afanasjevska, and A.V. Myenyaylov, "Stochastic optimization models and method in the turbomachines system improvement problem", in Proceedings of ASME-JSME-KSME Joint Fluids Engineering Conference, 24-29 July 2011, Hamamatsu, Japan. (AJK2011-22057). 
28. S.A. Aivazian, Z.I. Bezhaeva, and O.V. Staroverov, Multivariate observation classification. Moscow: Statistics, 1974.

29. V.I. Romanovsky, Applications of mathematical statistics in the test case. MoskowLeningrad: Gostechizdat, 1947.

30. V.I. Romanovsky, Mathematical statistics. Book 1. Fundamentals of the theory of probability and mathematical statistics. Tashkent: Publishing house of city of Uzbekistan Science Academy, 1961.

31. V.I. Romanovsky, Mathematical statistics. Book 2. Operational methods of mathematical statistics. Tashkent: Publishing house of city of Uzbekistan Science Academy, 1963.

32. A.N. Tikhonov and V.Y. Arsenin, Methods for solving ill-posed problems. Moscow: Science, 1986.

33. V.E. Strilets et. al., Systematic improvement of the elements of complex technical systems based on the concept of inverse problems: monograph. X.: Nat. aerospace. un-t them. N.E. Zhukovsky, Kharkiv Aviation Institute, 2013,148 p.

34. I.M. Antonyan, V.A. Hot, A.I. Zelensky, and E.M. Ugryumova, "Method for assessing the information content of variables of neural network models of systems and processes with data uncertainty", News of the Kharkiv National University. Zbirnik naukovyh prac. Seriya: "Mathematical modeling. Information technology. Automation and control systems", vol. 26, no. 1156, pp. 5-16, 2015.

35. V. Strilets, N. Bakumenko, S. Chernysh, M. Ugryumov, and V. Donets, "Application of artificial neural networks in the problems of the patient's condition diagnosis in medical monitoring systems", Integrated Computer Technologies in Mechanical Engineering - Synergetic Engineering. International Scientific and Technical Conference (ICTM 2019), 28-30 Nov. 2019, Kharkov, Ukraine, Springer Link: 2020, pp. 173-185. Available: https://doi.org/ 10.1007/978-3-030-37618-5_16s

Received 07.12.2020

From the Editorial Board: the article corresponds completely to submitted manuscript.

\section{INFORMATION ON THE ARTICLE}

Iryna O. Trofymova, ORCID: 0000-0002-1537-5601, National Aerospace University "Kharkiv Aviation Institute", Ukraine, e-mail: i.trofymova@khai.edu

Ievgen S. Meniailov, ORCID: 0000-0002-9440-8378, National Aerospace University "Kharkiv Aviation Institute", Ukraine, e-mail: j.menyailov@khai.edu

Serhii V. Chernysh, ORCID: 0000-0002-1750-5158, National Aerospace University "Kharkiv Aviation Institute", Ukraine, e-mail: mr.serhii.chernysh@gmail.com

Sergiy V. Yepifanov, ORCID: 0000-0003-0533-9524, National Aerospace University "Kharkiv Aviation Institute”, Ukraine, e-mail: s.yepifanov@khai.edu

Olexandr M. Khustochka, Scientific Research and Design ComplexState Enterprise Zaporizhzhia Machine-Building Design Bureau named after academician A.G. Ivchenko, Ukraine, e-mail: 03527@ivchenko-progress.com

Mykhaylo L. Ugryumov, ORCID: 0000-0003-0902-2735, V.N. Karazin Kharkiv National University, Ukraine, e-mail: m.ugryumov@karazin.ua

Andriy V. Myenyaylov, ORCID: 0000-0003-1407-1224, Commercial Aircraft Engine Co., Ltd, China, e-mail: myenyaylov@ukr.net

Dmytro I. Chumachenko, ORCID: 0000-0003-2623-3294, National Aerospace University “Kharkiv Aviation Institute”, Ukraine, e-mail: d.chumachenko@khai.edu 


\begin{abstract}
МЕТОДОЛОГІЯ НЕЛІНІЙНОГО РОБАСТНОГО ОЦІНЮВАННЯ ДЛЯ СИНТЕЗУ РОЗВ'ЯЗКІВ ОБЕРНЕНИХ ТА ПРЯМИХ БАГАТОДИСЦИПЛІНАРНИХ ЗАДАЧ У РОЗРАХУНКУ ІНЖЕНЕРНИХ РОЗМІРНИХ ЛАНЦЮГІВ НА ОСНОВІ ДИСКРЕТНИХ ДАНИХ ПРО АНАЛОГИ / І.О. Трофимова, С.С. Меняйлов, С.В. Черниш, С.В. Єпіфанов, О.М. Хусточка, М.Л. Угрюмов, А.В. Мєняйлов, Д.І. Чумаченко
\end{abstract}

\begin{abstract}
Анотація. Подано постановки обернених і прямих задач розрахунку інженерних розмірних ланцюгів на основі дискретних даних про аналоги і методології розв'язання цих задач. Показано, що задачі розрахунку прямих розмірних ланцюгів належать до класу обернених крайових задач у стохастичній постановці, які можна звести до багатокритеріальних задач стохастичної оптимізації зі змішаними умовами. Нова багатоетапна методологія пошуку розв'язків таких задач грунтується на методах нелінійного робастного оцінювання. Це може бути досягнуто шляхом розроблення ієрархічної дворівневої схеми синтезу розв'язків. На першому етапі схема включає ідентифікацію сурогатних моделей (у вигляді рівнянь регресіі). Другий етап - визначення ефективних робастних оцінок шуканих величин; невідомі величини оцінюються за апріорної i параметричної невизначеностей даних. Наведено результати розрахунків обернених і прямих задач проектування розмірних ланцюгів для двоступеневих осьових компресорів. Їх отримано за допомогою інтерактивної комп'ютерної системи підтримання прийняття рішень «ROD \& IDS».
\end{abstract}

Ключові слова: обернені крайові задачі в стохастичній постановці, апріорні і параметричні невизначеності, методи і системи оцінювання величин і процесів, теорія прийняття рішень.

МЕТОДОЛОГИЯ НЕЛИНЕЙНОГО РОБАСТНОГО ОЦЕНИВАНИЯ ДЛЯ СИНТЕЗА РЕШЕНИЙ ОБРАТНЫХ И ПРЯМЫХ МНОГОДИСЦИПЛИНАРНЫХ ЗАДАЧ РАСЧЕТА ИНЖЕНЕРНЫХ РАЗМЕРНЫХ ЦЕПЕЙ НА ОСНОВЕ ДИСКРЕТНЫХ ДАННЫХ ОБ АНАЛОГАХ / И.А. ТрофимОва, Е.С. Меняйлов, С.В. Черныш, С.В. Епифанов, А.Н. Хусточка, М.Л. Угрюмов, А.В. Меняйлов, Д.И. Чумаченко

Аннотация. Представлены постановки обратной и прямой задач расчета инженерных размерных цепей на основе дискретных данных об аналогах и методологии решения этих задач. Показано, что задачи расчета прямых размерных цепей относятся к классу обратных краевых задач в стохастической постановке, которые можно свести к многокритериальным задачам стохастической оптимизации со смешанными условиями. Новая многоэтапная методология поиска решений таких задач основана на методах нелинейного робастного оценивания. Это может быть достигнуто путем разработки иерархической двухуровневой схемы синтеза решений. На первом этапе схема включает идентификацию суррогатных моделей (в виде уравнений регрессии). Второй этап - определение эффективных робастных оценок искомых величин; неизвестные величины оцениваються при априорной и параметрической неопределенностях данных. Приведены результаты расчетов обратной и прямой задач проектирования размерных цепей для двухступенчатых осевых компрессоров. Они были получены с помощью интерактивной компьютерной системы поддержки принятия решений «ROD\&IDS».

Ключевые слова: обратные краевые задачи в стохастической постановке, априорные и параметрические неопределенности, методы и системы оценивания величин и процессов, теория принятия решений. 